Pragmatic Case Studies in Psychotherapy, http://pcsp.libraries.rutgers.edu

Volume 12, Module 2, Article 2, pp. 113-123 [copyright by author]

Commentary on The Impact of Implementing an "Incredible Years" Group Within a Family Living Unit in a Transitional Living Shelter: The Case of "Cathy"

\title{
Integrating Early Childhood Mental Health and Trauma-Informed Care for Homeless Families With Young Children
}

\author{
MARIAN E. WILLIAMS ${ }^{\mathrm{a}, \mathrm{b}}$ \\ ${ }^{\text {a }}$ Children's Hospital Los Angeles \\ b Correspondence regarding this article should be addressed to Marian E. Williams, PhD, USC University Center \\ for Excellence in Developmental Disabilities at Children’s Hospital Los Angeles, 4650 Sunset Blvd., MS\#53, Los \\ Angeles, CA 90027. \\ Email: mwilliams@chla.usc.edu.
}

\begin{abstract}
Rogers, Bobich, and Heppell’s (2016) case study illustrating the successful application of an "Incredible Years" intervention with a 4-year-old girl and her family in the context of a homeless shelter provides an opportunity to consider the intersecting perspectives of infant and early childhood mental health and trauma-informed care. Cathy's exposure to intimate partner violence, her mother's chronic depression, and her homelessness occurred during the critical developmental stages of prenatal development and the first four years of life, impacting her developing understanding of relationships and her emotion regulation. A trauma-informed perspective provides an understanding of the links between Cathy's history of trauma and her presenting symptoms of tantrums, aggression, and "moodiness," leading to recommended parenting strategies that support co-regulation and eventually self-regulation of emotions. Although the Incredible Years intervention was successful in reducing Cathy's symptoms, the addition of trauma-focused interventions may have the added benefit of helping Cathy to directly play and talk about her experience, together with her mother, so that both can understand and integrate their traumatic experiences and her mother can restore her role as a "protective shield" for her family. Finally, the opening provided by implementation of a successful parenting intervention could lead to a broader consultation aimed at creating a traumainformed organization within the transitional living shelter.
\end{abstract}

Key Words: early childhood; infant mental health; trauma-focused; homeless families; case study; clinical case study

In their compelling and comprehensive case study, Rogers, Bobich, and Heppell (2016) describe the novel implementation of an evidence-based parenting and social-emotional skills intervention, called the "Incredible Years" (IY) program (Webster-Stratton, 2011), with a mother and her two daughters in the context of a transitional living shelter for homeless mothers and 
Integrating Early Childhood Mental Health and Trauma-Informed Care

children. "Cathy," the primary focus of this case study, is a 4-year-old Latina girl, exposed to her father's verbal and physical assaults on her mother prenatally and for the first year of life, and living in five transitional settings (hotel and shelters) in the next three years of life. Further, Cathy experienced the chronic depression of her mother (from before her birth and continuing to the present) and exposure to unspecified "difficult situations" and "mentally unstable" people during her frequent moves. Thus, this case study provides a window into the impact of trauma on a young family, the experience of homelessness, the promise of positive intervention, and the resiliency of families. California, recently ranked number 48 out of 50 in an analysis of State responses to child homelessness (Bassuk, DeCandia, Beach, \& Berman, 2014), is clearly in need of innovative approaches to support families in this situation.

As a psychologist working in the same mental health center as Rogers and colleagues, one of the professional benefits of this environment is the collaboration and cross-fertilization of different clinical perspectives. I appreciate this opportunity to share my perspective as an infantfamily and early childhood mental health specialist, and to integrate that perspective with the trauma-informed care literature that has been growing in importance in the social services field and has been infused in Rogers et al.'s work. One of the values shared across our mental health center is the importance of evidence-based practice, and I appreciate the use of the Incredible Years model, an approach that has been systematically researched and found to be effective with a range of families whose children are exhibiting disruptive behaviors (Menting, Orobio de Castro, \& Matthys, 2013).

As noted by Rogers et al. (2016), many parents involved with the child welfare system or living in shelters are mandated to take parenting classes, yet rarely does that mandate come with an expectation that the parenting approach will be based in research evidence. In addition to a focus on evidence-based practice, as a program we also recognize the importance of adapting practices to fit the unique needs of the populations we serve. We have published previously on the process of applying evidence-based practice in psychology to our client population that includes primarily Latino, low-income families, many with comorbid chronic medical illness and developmental disability in addition to complex mental health needs (Williams, Rogers, Carson, Sherer, \& Hudson, 2011; Harley, Williams, Zamora, \& Lakatos, 2014; Williams, Carson, Zamora, Harley, \& Lakatos, 2014). Rogers et al.'s (2016) case study follows in this tradition by exploring the challenge and the promise in implementing the Incredible Years model within a unique setting.

\section{INFANT-FAMILY AND EARLY CHILDHOOD MENTAL HEALTH PERSPECTIVE}

Considering the trajectory of the first four years of Cathy's life, it is helpful to apply insights provided in the infant and early childhood mental health field. Zero to Three, the national organization, has defined infant-early childhood mental health as "the developing capacity of the child from birth to 5 years of age to form close relationships, manage and express emotions, and explore the environment and learn” (Zero to Three, 2016). Brandt (2014) details specific elements essential to optimal mental health development in young children: (1) a safe, healthy, low stress pregnancy; (2) the opportunity and ability to "fall in love" and "be in love" 
Integrating Early Childhood Mental Health and Trauma-Informed Care

for Homeless Families with Young Children

M.E. Williams

Pragmatic Case Studies in Psychotherapy, http://pcsp.libraries.rutgers.edu

Volume 12, Module 2, Article 2, pp. 113-123 [copyright by author]

with a safe and nurturing adult; (3) support in learning to self-regulate; (4) support in learning to mutually regulate; and (5) nurturing, contingent, and developmentally appropriate care (p. 16).

Translating these elements into intervention approaches, infant and early childhood mental health professionals focus their efforts on enhancing nurturing and supportive relationships between parent and child, helping parents to recognize the meaning of their child's behaviors and emotional responses, and to support their children's healthy social-emotional development. While many volumes have been written about infant mental health interventions, a seminal summary by Alicia Lieberman (1998) captures succinctly the key components still considered essential to an infant and early childhood mental health perspective: (1) relationships are the key to mental health and to intervention; (2) individual differences in young children and their parents must guide intervention approaches; (3) the environmental context "deeply affects the person's functioning” (p. 12); (4) to effectively intervene, we must understand the inner states that lead to external behaviors; and (5) the feelings and behaviors of the therapist impact intervention, thus leading to an emphasis on reflective practice within infant and early childhood mental health.

In the case of Cathy, a developmental perspective is helpful in understanding the impact of trauma on her developing sense of self and her ability to manage her emotions and interact in positive ways with others. Recent evidence demonstrates that intimate partner violence (IPV), such as that experienced by Cathy's mother, has profound impacts on the developing fetus before birth (Babenko, Kovalchuk, \& Metz, 2015). For example, in a longitudinal study of 119 children followed from prenatal to age 10 years, Martinez-Torteya, Bogat, Levendosky, and von Eye (2015) found that children exposed to IPV during pregnancy exhibited higher levels of internalizing and externalizing problems and high cortisol secretion before and after a stress challenge, even after controlling for exposure to IPV occurring during the child's life or recently.

Following birth, infants exposed to IPV, such as Cathy's experience in her first year of life, have an increased risk of adverse outcomes including impacts on the development of attachment relationships, early brain development, and the development of emotion regulation (Carpenter \& Stacks, 2009). While many parents (and others) assume that if a child is too young to put words to her experience and/or is asleep during incidents of IPV, these experiences will not adversely affect her. On the contrary, a study using functional MRI with 6- to 12-month-old infants found that those who had been exposed to interparental conflict responded to the sounds of angry adult voices during sleep with neural responses across brain regions associated with emotion and stress reactivity and regulation (Graham, Fisher, \& Pfeifer, 2013). In fact, children who are too young to develop a verbal narrative or use play to explain and ask about stressful experiences may experience even more distress than older children who have more coping strategies.

In their tool kit for service providers and administrators working with young homeless families, The National Center on Family Homelessness notes the impact of homelessness on young children depending on their stage of development (DeCandia, Bassuk, \& The National Center on Family Homelessness, 2012). In the first two years of life, the primary developmental 
Integrating Early Childhood Mental Health and Trauma-Informed Care

Pragmatic Case Studies in Psychotherapy, http://pcsp.libraries.rutgers.edu

Volume 12, Module 2, Article 2, pp. 113-123 [copyright by author]

tasks are to grow physically, to learn to trust that basic needs will be met, and to learn to interact with others through a focus on primary relationships with caregivers. Fears of abandonment and of not getting their needs met are typical early fears of young children and lead to emotional distress if a nurturing caregiver is not able to provide reassurance. For Cathy, witnessing IPV, experiencing her mother's postpartum depression, and their early homelessness in the first two years likely negatively influenced her sense that her primary caregivers were nurturing and safe, and her confidence that her basic needs would be met.

Later, in the developmental stage from age two to four years, developmental tasks come to include the growth of language and cognitive capacity, learning to interact with peers in addition to the primary caregivers, and learning to follow rules and regulate emotions. At this stage young children typically fear punishment and loss of control, and their egocentric orientation leads them to blame themselves for events that occur around them. Young children often express emotional upsets with behaviors rather than words, and rely heavily on the structure and support of nurturing adults to help them to manage their emotional states. During this stage of life, Cathy changed residences frequently, her mother remained depressed and anxious about her housing and financial situation, and the family was reportedly exposed to “mentally unstable” people while having no access to support from extended family or friends.

Children exposed to early trauma such as IPV can show resiliency when buffered by a caring adult presence. However, when trauma is impacting both child and parent, as in Cathy's situation, the parent's ability to create a "protective shield" (Pynoos, Steinberg, \& Piacentini, 1999; p. 1543) may be compromised. In the case of Cathy's mother, on the one hand she protected her daughter by leaving Cathy's abusive father and moving into shelter. But on the other hand, Cathy's mother's own experience of depression and her difficulty finding safe and adequate housing may have limited her capacity to help Cathy and her sister to feel safe and protected. Based on the case information provided, it seems likely that Cathy's mother was unable to provide a developmentally-appropriate narrative to help Cathy understand the events occurring in their lives, to reassure her that she was not at fault for upsetting events, to provide the routine structure that young children need to thrive, to help her regulate her emotions when distressed, and to give her confidence that her mother was a strong and protective adult who would provide safety for the family. From an infant and early childhood mental health framework, helping Cathy's mother to recognize the impact of traumatic events on her daughters' behaviors and her own functioning as a parent, and restoring her role as a protective shield for her daughters, would be a primary focus of intervention to match Cathy's developmental needs as a 4-year-old girl living in stressful circumstances.

\section{TRAUMA-INFORMED PERSPECTIVE}

When taking a trauma-informed approach to intervention with a child such as Cathy, the clinician asks not "What is wrong with this child?” but "What happened to this child?” (Bloom, 1994, quoting Federaro). This perspective helps to explain Cathy’s presenting symptoms, which included tantrums, physical aggression toward her sister, and extreme "moodiness" as trauma responses. Longitudinal and cross-sectional studies have demonstrated a strong relationship between childhood traumatic experiences and disruptive behaviors such as those displayed by 
Integrating Early Childhood Mental Health and Trauma-Informed Care

for Homeless Families with Young Children

M.E. Williams

Pragmatic Case Studies in Psychotherapy, http://pcsp.libraries.rutgers.edu

Volume 12, Module 2, Article 2, pp. 113-123 [copyright by author]

Cathy. For example, Kotch et al. (2008), in a longitudinal study of over 1000 children, found that neglect in the first two years of life predicted aggressive behavior at ages 4, 6, and 8 years. Macfie, Cicchetti, and Toth (2001) found that all types of maltreatment (including sexual abuse, physical abuse, and neglect) in preschoolers were associated with dissociative symptoms, which were in turn correlated with both externalizing and internalizing symptoms as rated by teachers. A study examining the developmental timing of traumatic events demonstrated that severity of emotional maltreatment (which included exposure to domestic violence) during the infant/toddler period predicted externalizing behavior and aggression in children aged 5 to 11 years, even if no further maltreatment occurred after the first two years of life (Manly, Kim, Rogosch, \& Cicchetti, 2001). Finally, an analysis of trauma and behavioral symptoms in preschoolers from economically disadvantaged families demonstrated that trauma symptoms fully mediated the association between maltreatment and both internalizing and externalizing behaviors (Milot, Ethier, St-Laurent, \& Provost, 2010).

Knowledge of the strong association between early maltreatment, dissociative symptoms and later disruptive behaviors may lead to important clinical understanding of the meaning of those behaviors, the child's internal experience of their own dysregulated behaviors, and the most appropriate parenting responses. In addition, chronic exposure to dysregulated adults and dysregulating environments leads to young children having a limited repertoire for self-soothing and self-calming. If dissociation, anxiety, or other internal distress is occurring simultaneously or shortly before an aggressive behavior, this may indicate a trauma trigger is the immediate cause of the behavior. The trauma trigger may not be obvious to the adult, as for example when a car backfiring startles a child who has witnessed intimate partner violence, and the child responds by hitting his younger brother. Or a preschool-aged child who has experienced neglect, food insecurity, or inconsistent feeding as an infant or toddler may tantrum when she is hungry and is told "no" to cookies before dinner. The tantrum may seem out of proportion to the situation, unless the parent understands the connection between the experience of hunger pangs and the memory (not necessarily conscious) of not having had adequate food in the past.

A parental response of ignoring the tantrum, or immediately providing a time out following the act of aggression, may miss an opportunity for supportive, trauma-informed parenting and provoke more extreme dysregulation. For example, an empathic response that acknowledges the child's distress and difficulty managing emotions, together with adult presence and support to calm down and try an alternative response, can help a traumatized child learn to regulate her emotions and behaviors. While a behavioral or social learning parenting theory may view adult narration of feelings and soothing presence as serving to positively reinforce inappropriate behavior (through attention), when viewed through a trauma framework this kind of adult scaffolding of emotion regulation helps young children to co-regulate, a necessary precursor to self-regulation.

The description of the implementation strategies used by the clinicians in Rogers et al. (2016) demonstrates a trauma-informed approach that recognized the possible traumatic origins of some of Cathy's behaviors, and was delivered by clinicians who had specialized training regarding the impact of trauma on children. For example, the diagnosis of Adjustment Disorder in this case study fits with this perspective of Cathy's behaviors as a response to the stressful 
Integrating Early Childhood Mental Health and Trauma-Informed Care

for Homeless Families with Young Children

M.E. Williams

Pragmatic Case Studies in Psychotherapy, http://pcsp.libraries.rutgers.edu

Volume 12, Module 2, Article 2, pp. 113-123 [copyright by author]

events in her life rather than representative of individual psychopathology. Several examples are provided in the case study of moments when Cathy seemed to be reacting to trauma triggers, and the clinicians responded with reassurance and narration while continuing to support emotion identification and regulation. In addition, the clinicians helped Cathy's mother to consider the link between Cathy's past experiences on her behaviors (rather than viewing her as a "devil”), and limiting her own behaviors (such as talking in front of Cathy about her financial worries) that may serve to create more stress and anxiety. Webster-Stratton and Reid (2010) provide additional trauma-informed recommendations in their discussion of adaptations of the Incredible Years parent training for families involved with the child welfare system, such as strategies for the implementation of ignoring and time out procedures that are sensitive to the unique needs of these families.

\section{TRAUMA-FOCUSED VERSUS PARENTING- SKILLS-FOCUSED INTERVENTION OPTIONS}

When we ask "What happened to this child," we find that Cathy's short life has been marked by exposure to angry, out of control, and dangerous adults; instability in her living situation; and chronic depression in her primary caregiver. Many young children present to therapy with this combination of exposure to trauma and disruptive behaviors. The clinician is then faced with a dilemma - whether to (1) focus on parenting skills that have been shown to reduce problem behaviors (thereby addressing the parent's primary concerns, helping the child to gain self-control and mastery, and helping the parent to develop positive parenting approaches and lessen ineffective strategies); or (2) focus directly on helping the child and parent to process, cope with, and integrate the trauma experience using a trauma-focused intervention.

In addition to Trauma-Focused Cognitive Behavior Therapy (TF-CBT; Cohen, Mannarino, \& Deblinger, 2006), mentioned by Rogers et al., Child-Parent Psychotherapy (CPP; Lieberman \& Van Horn, 2008) is a trauma-focused, dyadic, relationship-based therapy model specifically developed for children under age 5 years who have been exposed to trauma. In fact, CPP was originally developed and tested as an intervention for young children exposed to intimate partner violence (Lieberman, Ghosh Ippen, \& Van Horn, 2015) and has also been found to be effective with young children of depressed mothers (Cicchetti, Toth, \& Rogosch, 1999; Toth, Rogosch, Manly, \& Cicchetti, 2006), suggesting good applicability for a family such as Cathy's. And, although it does not focus on children's disruptive behaviors nor teach specific parenting strategies, it has been shown to significantly reduce behavioral problems in preschoolers exposed to domestic violence (DV) (Lieberman, Van Horn, \& Ghosh Ippen, 2005). For example, in a randomized controlled trial of CPP in comparison to community treatment for preschoolers exposed to DV, children receiving CPP showed significantly greater reductions in behavior problems as well as trauma symptoms (Lieberman et al., 2005), and these findings persisted at 6-month follow-up (Lieberman, Ghosh Ippen, \& Van Horn, 2006).

In Cathy’s case, since the trauma-informed approach to the Incredible Years (IY) program proved to be effective in reducing her disruptive behaviors and trauma symptoms, we might ask why a trauma-focused intervention would be needed or what more it might offer to Cathy and her mother. One important missing ingredient from the IY intervention provided in 
Integrating Early Childhood Mental Health and Trauma-Informed Care

for Homeless Families with Young Children

M.E. Williams

Pragmatic Case Studies in Psychotherapy, http://pcsp.libraries.rutgers.edu

Volume 12, Module 2, Article 2, pp. 113-123 [copyright by author]

this case study is an opportunity to talk directly with Cathy and her sister (and/or to help her mother talk with them directly) about the trauma and stress that the family has experienced. Young children experiencing traumatic events (such as observing their father assault their mother, or moving abruptly and without explanation from one shelter to another) develop their own understanding of what has occurred and what it means for their life. If that understanding is not tempered by support and narration from a loving adult, the conclusions they reach may be damaging rather than healing. For example, Cathy may come to the conclusion that adults are scary and unpredictable, that her mother is unable to protect her, and that she needs to physically attack others in order to be safe. Further, she may conclude that she has moved from one home to another because of some "bad" action on her part, or as a punishment. Hearing her mother call her a "devil," she may conclude that she is unworthy of love and inherently damaged.

In a trauma-focused intervention such as Child-Parent Psychotherapy, Cathy’s mother would be provided psychoeducation about the link between traumatic events and Cathy's behaviors, and explore the impact of her own trauma experiences on her parenting approaches. She would then be supported in the process of explaining to Cathy, through developmentally appropriate play and narration, what has happened in Cathy's life and how her mother is now learning to protect and guide her. Through play, Cathy would have the opportunity to show and talk with her mother about what happened to her, and receive empathy as well as age-appropriate explanations of any inaccuracies in her understanding. When aggressive behaviors and tantrums occur during the course of therapy, Cathy's mother would be supported in recognizing the communication within the behavior, recognizing links to trauma triggers or internal emotional dysregulation, and responding in supportive, nurturing, and protective ways while setting appropriate limits and structure.

On the other hand, not every family is able or willing to address trauma directly, especially when in crisis or at the beginning of their introduction into the social service system. In Cathy's case, her mother had been offered mental health services for herself and for her children, and had declined them. However, when offered a parenting class to help her with Cathy's disruptive behaviors, she readily signed up. And, possibly through the inclusion of their trauma-informed perspective in the delivery of the parenting approach, the clinicians in this case study were able to shift Cathy's mother's perspective such that she adopted a more traumainformed view of herself and her daughters' experiences, and in the end was open to further treatment for herself and for them. Therefore, in this case, it seems the best approach turned out to be the one that started with the parent's immediate priorities, was relatively non-stigmatizing, provided an intervention that fit well within the structure and schedule of the homeless shelter, resulted in a reduction in problem symptoms within a relatively short time period, and provided a door that this parent was able to step through toward positive changes for herself and her family.

\section{INTEGRATION OF PARENTING SKILL AND TRAUMA-FOCUSED APPROACHES?}

Perhaps one more modification that would retain the advantages of the Incredible Years implementation as delivered in Rogers et al. (2016), while including some of the advantages of a trauma-focused approach, would be to develop an additional Incredible Years parent module 
Integrating Early Childhood Mental Health and Trauma-Informed Care

Pragmatic Case Studies in Psychotherapy, http://pcsp.libraries.rutgers.edu

Volume 12, Module 2, Article 2, pp. 113-123 [copyright by author]

focused on psychoeducation about trauma. Such a module might include the following topics for parent training: (1) the link between traumatic experiences and disruptive behaviors; (2) learning to recognize when a behavior may have been a response to a trauma trigger; (3) differential parenting responses when behaviors seem to be elicited by trauma triggers versus oppositional behavior; (4) parenting strategies that increase children's safety and put the parent in the role of "protective shield"; (5) talking to and playing with children about their traumatic past experiences, and ways to respond as a parent when the child brings up stressful experiences in play or verbally. The National Child Traumatic Stress Network (NCTSN) Core Curriculum for Trauma includes core trauma principles that could be integrated into such a module, and additional training materials are being developed (NCTSN Core Curriculum on Childhood Trauma Task Force, 2012).

\section{ONE STEP FURTHER: SUPPORTING TRAUMA-INFORMED ORGANIZATIONS}

Before we leave Cathy and her family, it is important to consider the impact that mental health consultants such as the Rogers et al. team can have on the larger context of the transitional living shelter. This issue was touched on in the mention of a larger role for the mental health team in talking with shelter staff about the need for trauma-informed interventions, and offering additional mental health services (both at the shelter and at the mental health clinic) for families. Some informative materials have been developed to support shelters such as this one in developing a more trauma-informed approach to all families served; two resources in particular seem particularly useful for this setting. Through a partnership between the Substance Abuse and Mental Health Services Administration, the National Child Traumatic Stress Network, and others, Prescott, Soares, Konnath, and Bassuk (2008) developed a guide for creating traumainformed services for mothers and children experiencing homelessness. The guide includes practical strategies and approaches to developing a trauma-informed atmosphere and environment for families in a homeless shelter; developing policies, procedures, services, and supports that are trauma-informed; and providing training and supervision for staff. Another guide, focused on families with young children experiencing homelessness, was developed by The National Center on Family Homelessness in partnership with Zero to Three (DeCandia et al., 2012). Finally, the National Center on Family Homelessness has teamed up with American Institutes for Research (AIR) to develop frameworks across service sectors for building and evaluating trauma-informed organizations.

With the foot-in-the-door provided by the request for parent training and its effective implementation, this team of psychologists has the potential to go one step further, partnering with shelter providers and administrators to develop transformative, trauma-informed care reaching many families.

\section{REFERENCES}

Babenko, O., Kovalchuk, I., \& Metz, G. A. S. (2015). Stress-induced perinatal and transgenerational epigenetic programming of brain development and mental health. Neuroscience \& Biobehavioral Reviews, 48, 70-91. 
Integrating Early Childhood Mental Health and Trauma-Informed Care

for Homeless Families with Young Children

M.E. Williams

Pragmatic Case Studies in Psychotherapy, http://pcsp.libraries.rutgers.edu

Volume 12, Module 2, Article 2, pp. 113-123 [copyright by author]

Bassuk, E. L., DeCandia, C. J., Beach, C. A., \& Berman, F. (2014). America's youngest outcasts: Report card on child homelessness. Waltham, MA: The National Center on Family Homelessness, American Institutes for Research. Retrieved from http://www.air.org/resource/americas-youngest-outcasts-report-card-child-homelessness.

Bloom, S.L. (1994). The Sanctuary model: Developing generic inpatient programs for the treatment of psychological trauma. In M.B. Williams and J.F. Sommer (Eds), Handbook of post-traumatic therapy: A practical guide to intervention, treatment, and research (pp. 474-449). Westport, CT: Greenwood Publishing.

Brandt, K. (2014). Core concepts in infant-family and early childhood mental health. In K. Brandt, B. D. Perry, S. Seligman, \& E. Tronick (Eds), Infant and early childhood mental health: Core concepts and clinical practice (pp. 1-20). Washington, DC: American Psychiatric Publishing.

Carpenter, G. L. \& Stacks, A. M. (2009). Developmental effects of exposure to intimate partner violence in early childhood: A review of the literature. Child and Youth Services Review, 31, 831-839.

Cicchetti, D., Toth, S. L., \& Rogosch, F. A. (1999). The efficacy of toddler-parent psychotherapy to increase attachment security in offspring of depressed mothers. Attachment \& Human Development, 1, 34-66.

Cohen, J. A., Mannarino, A. P., \& Deblinger, E. (2006). Treating trauma and traumatic grief in children and adolescents. New York, NY: Guilford Press.

DeCandia, C., Bassuk, E., \& The National Center on Family Homelessness (2012). Meeting the needs of young families experiencing homelessness: A guide for service providers and program administrators. Needham Heights, MA: The National Center on Family Homelessness. Retrieved from http://www.air.org/project/strengthening-risk-andhomeless-young-mothers-and-children.

Graham, A. M., Fisher, P. A., \& Pfeifer, J. H. (2013). What sleeping babies hear: A functional MRI study of interparental conflict and infants' emotion processing. Psychological Science, 24, 782-789.

Harley, E., Williams, M. E., Zamora, I., \& Lakatos, P. P. (2014). Trauma treatment in young children with developmental disabilities: Applications of the Child-Parent Psychotherapy model to the cases of “James” and “Juan.” Pragmatic Case Studies in Psychotherapy, 10, 156-195.

Kotch, J. B., Lewis, T., Hussey, J. M., English, D., Thompson, R., Litrownik, A. J., Runyan, D. K., Bangdiwala, S. I., Margolis, B., \& Dubowitz, H. (2008). Importance of early neglect for childhood aggression. Pediatrics, 121, 725-731.

Lieberman, A. (1998). A perspective on infant mental health. The Signal, 6, 11-12. Retrieved from http://www.waimh.org/i4a/pages/index.cfm?pageid=3315.

Lieberman, A. F., Ghosh Ippen, C., Van Horn, P. J. (2006). Child-Parent Psychotherapy: Six month follow-up of a randomized control trial. Journal of the American Academy of Child and Adolescent Psychiatry, 45(8), 913-918.

Lieberman, A. F., Ghosh Ippen, C., \& Van Horn, P. J. (2015). Don't hit my mommy: A manual for Child-Parent Psychotherapy with young witnesses of family violence ( $2^{\text {nd }}$ Ed). Washington, DC: Zero to Three Press. 
Integrating Early Childhood Mental Health and Trauma-Informed Care for Homeless Families with Young Children

M.E. Williams

Pragmatic Case Studies in Psychotherapy, http://pcsp.libraries.rutgers.edu

Volume 12, Module 2, Article 2, pp. 113-123 [copyright by author]

Lieberman, A. F. \& Van Horn, P. J. (2008). Psychotherapy with infants and young children: Repairing the effects of stress and trauma on early attachment. New York, NY: Guilford Press.

Lieberman, A. F., Van Horn, P. J., \& Ghosh Ippen, C. (2005). Toward evidence-based treatment: Child-Parent Psychotherapy with preschoolers exposed to marital violence. Journal of the American Academy of Child and Adolescent Psychiatry, 44, 1241-1248.

Macfie, J., Cicchetti, D. \& Toth, S. L. (2001). Dissociation in maltreated versus nonmaltreated preschool-aged children. Child Abuse and Neglect, 25, 1253-1267.

Manly, J. T., Kim, J. E., Rogosch, F. A., \& Cicchetti, D. (2001). Dimensions of child maltreatment and children's adjustment: Contributions of developmental timing and subtype. Development and Psychopathology, 13, 759-782.

Martinez-Torteya, C., Bogat, G. A., Levendosky, A. A., \& von Eye, A. (2015). The influence of prenatal intimate partner violence exposure on hypothalamic-pituitary-adrenal axis reactivity and childhood internalizing and externalizing symptoms. Development and Psychopathology, 28, 55-72.

Menting, A. T. A., Orobio de Castro, B., \& Matthys, W. (2013). Effectiveness of the Incredible Years parent training to modify disruptive and prosocial child behaviors: A meta-analytic review. Clinical Psychology Review, 33, 901-913.

Milot, T., Ethier, L. S., St-Laurent, D., \& Provost, M. A. (2010). The role of trauma symptoms in the development of behavior problems in maltreated preschoolers. Child Abuse and Neglect, 34, 225-234.

NCTSN Core Curriculum on Childhood Trauma Task Force (2012). The 12 core concepts: Concepts for understanding traumatic stress responses in children and families. Core Curriculum on Childhood Trauma. Los Angeles, CA and Durham, NC: UCLA-Duke University National Center for Traumatic Stress. Retrieved from http://nctsn.org/resources/audiences/parents-caregivers/what-is-cts/12-core-concepts.

Prescott, L., Soares, P., Konnath, K., \& Bassuk, E. (2008). A long journey home: A guide for creating trauma-informed services for mothers and children experiencing homelessness. Rockville, MD: Center for Mental Health Services, Substance Abuse and Mental Health Services Administration; and the Daniels Fund; National Child Traumatic Stress Network; and the W.K. Kellogg Foundation. Retrieved from www.homeless.samhsa.gov

Pynoos, R. S., Steinberg, A. M. \& Piacentini, J. C. (1999). A developmental psychopathology model of childhood traumatic stress and intersection with anxiety disorders. Biological Psychiatry, 46, 1542-1554.

Rogers, K.C., Bobich, M., \& Heppell, P. (2016). The impact of implementing an "Incredible Years" group within a family living unit in a transitional living shelter: The case of "Cathy." Pragmatic Case Studies in Psychotherapy, 12(2), Article 1, 65-112. Available: pcsp.libraries.rutgers.edu

Toth, S. L., Rogosch, F. A., Manly, J. T., \& Cicchetti, D. (2006). The efficacy of toddler-parent psychotherapy to reorganize attachment in the young offspring of mothers with major depressive disorder: A randomized preventive trial. Journal of Consulting and Clinical Psychology, 74, 1006-1016.

Webster-Stratton, C. (2011). The Incredible Years parent, teachers, and children's training series: Program content, methods, research and dissemination, 1980-2011. Seattle, WA: 
Incredible Years, Inc. Retrieved from http://incredibleyears.com/books/iy-trainingseries-book/.

Webster-Stratton, C. \& Reid, M. J. (2010). Adapting the Incredible Years, an evidence-based parenting programme, for families involved in the child welfare system. Journal of Children's Services, 5, 25-42.

Williams, M. E., Carson, M. C., Zamora, I., Harley, E. K., \& Lakatos, P. P. (2014). Child-Parent Psychotherapy in the context of the developmental disability and medical service systems. Pragmatic Case Studies in Psychotherapy, 10, 212-226.

Williams, M. E., Rogers, K. C., Carson, M.C., Sherer, S., Hudson, B. (2012). Opportunities arising from transformation from treatment as usual to evidence-based practice. Professional Psychology: Research and Practice, 43(1), 9-16.

Zero to Three (2016). Infant-early childhood mental health. Retrieved from https://www.zerotothree.org/resources/110-infant-early-childhood-mental-health. 